39. Tsutsumi Y, Fukuma S, Tsuchiya A, et al. Computed tomography during initial management and mortality among hemodynamically unstable blunt trauma patients: a nationwide retrospective cohort study. Scand J Trauma Resusc Emerg Med. 2017;25(1):74. doi:10.1186/s13049-017-0396-7

40. Linder F, Mani K, Juhlin C, Eklöf H. Routine whole body $\mathrm{CT}$ of high energy trauma patients leads to excessive radiation exposure. Scand J Trauma Resusc Emerg Med. 2016;24:7. doi:10.1186/ s13049-016-0199-2

41. Gordic S, Alkadhi H, Hodel S, et al. Whole-body CT-based imaging algorithm for multiple trauma patients: radiation dose and time to diagnosis. $\mathrm{Br} \mathrm{J}$ Radiol. 2015;88(1047):20140616. doi:10.1259/bjr. 20140616
42. Van Arnem KA, Supinski DP Jr, Tucker JE, Varney S. Cumulative effective radiation dose received by blunt trauma patients arriving to a military level I trauma center from point of injury and interhospital transfers. Am J Emerg Med. 2016; 34(12):2397-2401. doi:10.1016/j.ajem.2016.09.018 43. Banaste N, Caurier B, Bratan F, Bergerot JF, Thomson V, Millet I. Whole-body CT in patients with multiple traumas: factors leading to missed injury. Radiology. 2018;289(2):374-383. doi:10.1148/radiol. 2018180492

44. Giannakopoulos GF, Saltzherr TP, Beenen LF, et al; REACT Study Group. Missed injuries during the initial assessment in a cohort of 1124 level-1 trauma patients. Injury. 2012;43(9):1517-1521. doi: 10.1016/j.injury.2011.07.012
45. Christner JA, Kofler JM, McCollough CH. Estimating effective dose for CT using dose-length product compared with using organ doses: consequences of adopting International Commission on Radiological Protection publication 103 or dual-energy scanning. AJR Am J Roentgenol. 2010;194(4):881-889. doi:10.2214/AJR.09.3462

46. Mayo-Smith WW, Hara AK, Mahesh M, Sahani DV, Pavlicek W. How I do it: managing radiation dose in CT. Radiology. 2014;273(3):657-672. doi:10. 1148/radiol.14132328

\title{
Low-Dose Whole-Body Computed Tomography and Radiation Exposure in Patients With Trauma-Trust, but Verify
}

Laura N. Purcell, MD, MPH; Anthony Charles, MD, MPH

In an attempt to minimize missed injury rates, potentially decrease mortality, and enhance rapid patient disposition, standard-dose whole-body computed tomographic (WBCT) imaging has become ubiquitous at trauma centers for the hemodynami-

$\leftarrow$

Related article page 224 cally stable patient admitted with trauma. ${ }^{1,2}$ The radiation dose from WBCT ranges from 10 to $20 \mathrm{mGy}$, which results in an approximately $0.08 \%$ estimated lifetime cancer mortality for 45 -year-old persons. ${ }^{3}$ Risk of mortality due to missed injury is therefore higher than the risk of future radiation-induced cancer.

In this issue of JAMA Surgery, Stengel and colleagues ${ }^{4}$ show no increased odds of missed injury with low-dose WBCT. Remarkably, and of concern, the sensitivity for low-dose WBCT was low in cases of hemothorax (40.0\%), hollow visceral tears (0\%), hemoperitoneum (28.6\%), splenic rupture (64.7\%), and retroperitoneal bleeding (33.3\%). Furthermore, the baseline rates of missed injuries were high for both standard- and low- dose WBCT. Studies show missed injury rates resulting in change in treatment plans range from $2.4 \%{ }^{5}$ to $19 \% .^{6,7}$ A more normalized missed injury rate in the standard-dose WBCT in this study will show a statistically significant increase in odds of missed injury in the low-dose WBCT cohort. There is a tradeoff between low-dose radiation exposure and image quality. The validity of the model-based iterative reconstruction used and the accuracy of the interpretation of the derived images needs further scrutiny.

Whole-body computed tomography, commonly known by the euphemism "Pan Scan," is here to stay. This study by Stengel and colleagues ${ }^{4}$ certainly moves the needle in the direction of radiation exposure reduction. Before we fully embrace low-dose WBCT, trauma surgeons and radiologists need to be confident in the fidelity of the acquired images and the accuracy of their interpretation. Therefore, we must heed the words of the old Russian proverb: doveryai, no proveryai (trust, but verify).

\section{ARTICLE INFORMATION}

Author Affiliations: Department of Surgery, Division of Trauma and Acute Care Surgery, University of North Carolina at Chapel Hill.

Corresponding Author: Anthony Charles, MD, MPH, Department of Surgery, Division of Trauma and Acute Care Surgery, University of North Carolina at Chapel Hill, 101 Manning Dr, Chapel Hill, NC 27599 (anthony_charles@med.unc.edu).

Published Online: January 15, 2020

doi:10.1001/jamasurg.2019.5469

Conflict of Interest Disclosures: None reported.

\section{REFERENCES}

1. Self ML, Blake AM, Whitley M, Nadalo L, Dunn E. The benefit of routine thoracic, abdominal, and pelvic computed tomography to evaluate trauma patients with closed head injuries. Am J Surg. 2003; 186(6):609-613. doi:10.1016/j.amjsurg.2003.08.003

2. Pal JD, Victorino GP. Defining the role of computed tomography in blunt abdominal trauma: use in the hemodynamically stable patient with a depressed level of consciousness. Arch Surg. 2002; 137(9):1029-1032. doi:10.1001/archsurg.137.9.1029

3. Brenner DJ, Elliston CD. Estimated radiation risks potentially associated with full-body CT screening. Radiology. 2004;232(3):735-738. doi:10.1148/radiol. 2323031095

4. Stengel D, Mutze S, Güthoff $C$, et al. Association of low-dose whole-body computed tomography with missed injury diagnoses and radiation exposure in patients with blunt multiple trauma [published online January 15, 2020]. JAMA Surg. doi:10.1001/jamasurg.2019.5468
5. Yoong S, Kothari R, Brooks A. Assessment of sensitivity of whole body CT for major trauma. Eur J Trauma Emerg Surg. 2019;45(3):489-492. doi:10. 1007/s00068-018-0926-7

6. Banaste N, Caurier B, Bratan F, Bergerot JF, Thomson V, Millet I. Whole-body CT in patients with multiple traumas: factors leading to missed injury. Radiology. 2018;289(2):374-383. doi:10.1148/radiol. 2018180492

7. Salim A, Sangthong B, Martin M, Brown C, Plurad $D$, Demetriades $D$. Whole body imaging in blunt multisystem trauma patients without obvious signs of injury: results of a prospective study. Arch Surg. 2006;141(5):468-473. doi:10.1001/archsurg.141.5.468 